\title{
Study of Selected Metals Distribution, Source Apportionment, and Risk Assessment in Suburban Soil, Pakistan
}

\author{
Javed Iqbal and Munir H. Shah \\ Department of Chemistry, Quaid-i-Azam University, Islamabad 45320, Pakistan \\ Correspondence should be addressed to Javed Iqbal; jianas@yahoo.com.sg and Munir H. Shah; mhshahg@qau.edu.pk
}

Received 7 December 2014; Revised 8 March 2015; Accepted 26 May 2015

Academic Editor: Rita Rosa Plá

Copyright (C) 2015 J. Iqbal and M. H. Shah. This is an open access article distributed under the Creative Commons Attribution License, which permits unrestricted use, distribution, and reproduction in any medium, provided the original work is properly cited.

\begin{abstract}
Composite soil samples collected from suburban areas were analyzed for $\mathrm{Cd}, \mathrm{Co}, \mathrm{Cr}, \mathrm{Cu}, \mathrm{Fe}, \mathrm{Mn}, \mathrm{Pb}, \mathrm{Sr}$, and $\mathrm{Zn}$ by atomic absorption spectrophotometry. Based on pseudototal metal analysis, $\mathrm{Fe}, \mathrm{Mn}, \mathrm{Sr}$, and $\mathrm{Zn}$ were the prevailing metals while $\mathrm{Cd}, \mathrm{Co}, \mathrm{Cr}$, and $\mathrm{Pb}$ were the least participants. However, based on bioavailability, $\mathrm{Cd}, \mathrm{Co}, \mathrm{Pb}$, and $\mathrm{Sr}$ were easily leachable and might pose adverse effects to soil biota. In ecological risk assessment, contamination factor demonstrated moderate contamination by $\mathrm{Co}, \mathrm{Sr}$, and $\mathrm{Zn}$ and high contamination by $\mathrm{Cd}, \mathrm{Cu}$, and $\mathrm{Pb}$; geoaccumulation index indicated heavy to extreme contamination by $\mathrm{Cd}$ and heavy contamination by $\mathrm{Pb}$; enrichment factor revealed significant enrichment by $\mathrm{Co}, \mathrm{Cr}, \mathrm{Cu}, \mathrm{Mn}, \mathrm{Sr}$, and $\mathrm{Zn}$ and extreme enrichment by $\mathrm{Cd}$ and $\mathrm{Pb}$. Substantial human inputs for $\mathrm{Cd}, \mathrm{Co}, \mathrm{Cr}, \mathrm{Cu}, \mathrm{Mn}, \mathrm{Pb}, \mathrm{Sr}$, and $\mathrm{Zn}$ were also revealed by principal component analysis in the examined soil. Overall the study area was found to be contaminated at considerable/high degree.
\end{abstract}

\section{Introduction}

Recently, there has been considerable concern pertaining to soil contamination due to rapid industrialization, urbanization, and intense human activities, particularly contamination by different heavy metals [1-4]. Metals are the most studied soil pollutants because of their ubiquity, toxicity, and persistence. Some metals are essential for the metabolism of living organisms at low concentrations but, above certain levels, they become toxic [5-7]. Major anthropogenic sources of the metals include mining, waste disposal, fertilizers, traffic emission (vehicle exhaust, tire wear, and brake lining wear), industrial effluents, domestic emissions, and atmospheric depositions [8-10]. Metals accumulation in soil is of great concern due to their potential ecological risks and damaging effects on soil ecosystems $[1,11]$. Thus, it is necessary to quantify the extent of metals contamination and associated ecological risks of soil to potential receptors.

The pseudototal/total concentrations of metals in soil are useful indicators of contamination and ecological risk assessment $[12,13]$. However, total contents do not provide enough information about potential mobility, bioavailability, and toxicity of the metals $[14,15]$. Recently, bioavailability of the metals in soil has become an important consideration for many researchers $[14,16,17]$. Several methods have been designed to simulate and quantify the metal reactivity as well as the physicochemical and biologically available pools of the metals in soil [17]. One of the most popular methods for estimating metal bioavailability is chemical extraction by means of various mild to strong extracting agents, resulting in operationally defined specific metal fractions [18]. The assumption in these chemical extraction approaches is that the extracted metals are mobile and easily available for plants and leaching to groundwater and/or could possibly be detrimental to soil biota [19]. Therefore, efforts should also be focused on measurement of bioavailable fractions of selected metals.

The present study aimed to (1) investigate concentrations of $\mathrm{Cd}, \mathrm{Co}, \mathrm{Cr}, \mathrm{Cu}, \mathrm{Fe}, \mathrm{Mn}, \mathrm{Pb}, \mathrm{Sr}$, and $\mathrm{Zn}$ in soil during summer and winter seasons, (2) determine their associated ecological risks, (3) identify pollution sources by principal component analysis, and (4) find out bioavailability of these metals to soil biota. 


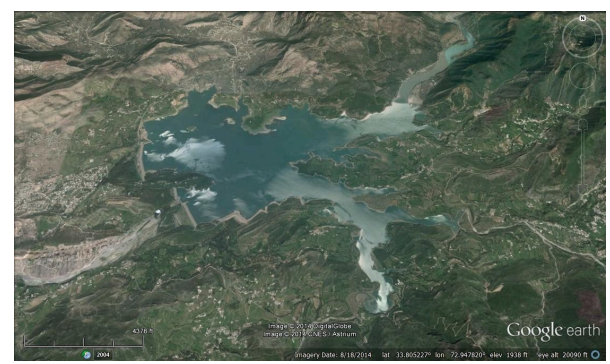

FIGURE 1: Locations map of the study area.

\section{Materials and Methods}

2.1. Site Description. In present study, soil samples were collected around Khanpur Lake $\left(72^{\circ} 56^{\prime} \mathrm{E}, 33^{\circ} 48^{\prime} \mathrm{N}\right)$ which is located on Haro River near the town of Khanpur, about $40 \mathrm{~km}$ northwest of Islamabad, Pakistan (Figure 1). It supplies drinking water to Islamabad and Rawalpindi and irrigation water to the surrounding agricultural areas. It was constructed in 1983 with the storage capacity of 140 million $\mathrm{m}^{3}$. Its average water depth is about $15 \mathrm{~m}$. The gross storage of the reservoir is $0.132 \mathrm{~km}^{3}$ with a total catchment area of $798 \mathrm{~km}^{2}$. The surface area of the reservoir varies from a maximum of 1806 ha to a minimum of 215 ha. The surrounding area of the lake is planted with flowering trees and set with gardens, picnic points, and isolated paths. The water stored in Khanpur Lake is fed by melting snow, seasonal rains, and the natural springs of Margalla Hills, Pakistan.

2.2. Sampling, Processing, and Chemical Analysis. A total of 80 composite surface $(1-10 \mathrm{~cm}$ top layer) soil samples (each containing 5-10 subsamples) were collected from residential and picnic areas around the lake in summer (June 2012) and winter (January 2013) in precleaned zip-locked polythene bags using a plastic scoop. To determine pseudototal metal contents, the soil samples were oven dried, grounded, homogenized, sieved through a $2 \mathrm{~mm}$ plastic sieve to remove stones, gravels, and coarse particles, and then stored in zip-locked polythene bags before chemical analysis $[6,20]$.

To find out the pseudototal metal concentrations, the soil sample (1-2 g, dry weight) was digested using freshly prepared acid mixture of $\mathrm{HNO}_{3}$ and $\mathrm{HCl}(3: 1, \mathrm{v} / \mathrm{v})$ in a microwave system [21]. Each digested sample was then filtered through fine filter paper $(0.45 \mu \mathrm{m}$, pore size $)$ and then diluted with $1 \% \mathrm{HNO}_{3}$ [22]. A reagent blank was also prepared having the same amount of acids without the sample with each batch.

A selective single step extraction procedure, using $0.1 \mathrm{M}$ $\mathrm{Ca}\left(\mathrm{NO}_{3}\right)_{2}$, was performed at room temperature to determine the bioavailable metal contents [16]. An aliquot of $5.0 \mathrm{~g}$ of air dried soil sample was added to $50 \mathrm{~mL}$ solution of $0.1 \mathrm{M}$ $\mathrm{Ca}\left(\mathrm{NO}_{3}\right)_{2}$ and the extraction was performed in precleaned glass vessel by shaking on an autoshaker@240 vibrations per minute for $16 \mathrm{~h}$. A reagent blank was also prepared with the same amount of $0.1 \mathrm{M} \mathrm{Ca}\left(\mathrm{NO}_{3}\right)_{2}$ solution without soil sample. Solid residue was separated from the extracts through filtration using fine filter papers [16, 23, 24]. The extractions were carried out in triplicate for each sample.
TABLE 1: Metal concentrations ( $\mathrm{mg} / \mathrm{kg}$ ) and recoveries (\%) in standard reference material (SRM-2711).

\begin{tabular}{lccc}
\hline Metal & $\begin{array}{c}\text { Certified } \\
\text { concentration } \\
(\mathrm{mg} / \mathrm{kg})\end{array}$ & $\begin{array}{c}\text { Measured } \\
\text { concentration } \\
(\mathrm{mg} / \mathrm{kg})\end{array}$ & $\begin{array}{c}\text { Recovery } \\
(\%)\end{array}$ \\
\hline $\mathrm{Cd}$ & 41.7 & 40.98 & 98 \\
$\mathrm{Co}$ & 10 & 9.7 & 97 \\
$\mathrm{Cr}$ & 47 & 47.56 & 101 \\
$\mathrm{Cu}$ & 114 & 112.3 & 99 \\
$\mathrm{Fe}$ & 28900 & 27601 & 96 \\
$\mathrm{Mn}$ & 638 & 642 & 101 \\
$\mathrm{~Pb}$ & 1162 & 1180 & 102 \\
$\mathrm{Sr}$ & 245.3 & 241.7 & 99 \\
$\mathrm{Zn}$ & 350.4 & 341 & 97 \\
\hline
\end{tabular}

The concentrations of $\mathrm{Cd}, \mathrm{Co}, \mathrm{Cr}, \mathrm{Cu}, \mathrm{Fe}, \mathrm{Mn}, \mathrm{Pb}, \mathrm{Sr}$, and $\mathrm{Zn}$ in $\mathrm{Ca}\left(\mathrm{NO}_{3}\right)_{2}$ and acid-extracts were measured using flame atomic absorption spectrophotometer (Shimadzu AA-670, Japan) under optimum analytical conditions. Selected metals concentrations were estimated by following calibration line method and dilutions were done duly whenever needed [20, 23].

2.3. Quality Control and Quality Assurance. Analytical grade chemicals were used throughout the study. All the reagents and calibration standards were prepared using deionized water. The preparation of calibration metal standards from stock solutions of $1000 \mathrm{mg} / \mathrm{L}$ was carried out by succeeding dilutions with deionized water. All glassware used was soaked overnight in $\mathrm{HNO}_{3}$ solution $(10 \%, \mathrm{v} / \mathrm{v})$ and then rinsed thoroughly with several portions of distilled water prior to use [22]. The reagent blanks were prepared throughout chemical analysis and were used to correct the analytical results. Reproducibility of the results was also ensured following analysis sequence of calibration of standards and blind standard solution analysis as unknown (quality control solutions). Standard reference material (SRM 2711) was also analyzed as part of the quality assurance and quality control (QA/QC) procedure and good agreement was observed between the data got from present study and the certified values (Table 1). Some soil samples were also analyzed at an independent laboratory for cross comparison and a maximum of $\pm 2.5 \%$ difference was observed in the two results. All the measurements were made in triplicate.

2.4. Statistical Analysis. The analyzed data were summarized using basic statistical parameters such as minimum, maximum, median, arithmetic mean, geometric mean, harmonic mean, skewness, and coefficients of variation. STATISTICA software was used for multivariate statistical analysis such as principal component analysis (PCA) of the obtained data [25]. PCA was applied both to discriminate between various geogenic inputs that cause variations in soil composition and to find out pollution sources affecting the metal levels of soil [20, 26-28]. It was employed to investigate the associations among selected metals and their grouping into 
a small number of factors. After grouping, metals within each factor are highly associated among themselves than with metals in other factors. Varimax rotation was applied as it minimizes the number of variables with a high loading on each component and assists in the explication of results. PCA with Varimax rotation was performed on log-transformed data.

2.5. Ecological Risk Assessment. Contamination levels of Cd, $\mathrm{Co}, \mathrm{Cr}, \mathrm{Cu}, \mathrm{Fe}, \mathrm{Mn}, \mathrm{Pb}, \mathrm{Sr}$, and $\mathrm{Zn}$ were assessed using contamination factor (CF) and degree of contamination $\left(C_{\mathrm{deg}}\right)$. The $\mathrm{CF}$ is calculated using the following equation as suggested by Hakanson [29]:

$$
\mathrm{CF}=\frac{C_{n}}{C_{b}},
$$

where $C_{n}$ and $C_{b}$ are the average concentrations of a metal in the studied and the preindustrial soil, respectively. The CF is the single-element index whereas $C_{\text {deg }}$ is a multielement index which is computed by adding contamination factors of all metals studied as

$$
C_{\mathrm{deg}}=\sum_{i=1}^{i=n} \mathrm{CF} .
$$

In this study, mean concentrations of elements in continental earth's crust [30] were used as reference values as suggested by Loska et al. [31]. The results were interpreted as [29] CF $<1$ = low contamination, $1 \leq \mathrm{CF}<3=$ moderate contamination, $3 \leq \mathrm{CF}<6=$ considerable contamination, $6 \leq \mathrm{CF}=$ very high contamination, $C_{\mathrm{deg}}<8=$ low degree of contamination, 8 $\leq C_{\mathrm{deg}}<16=$ moderate degree of contamination, $16 \leq C_{\mathrm{deg}}<$ 32 = considerable degree of contamination, and $32 \leq C_{\mathrm{deg}}=$ very high degree of contamination.

The $I_{\text {geo }}$ estimates contamination by comparing preindustrial and studied metal concentrations [32]. It is calculated using the following equation:

$$
I_{\text {geo }}=\log _{2}\left(\frac{C_{n}}{1.5 B_{n}}\right),
$$

where $C_{n}$ is the mean content of element examined in soil and $B_{n}$ is the geochemical background concentration in continental earth crust. The factor, 1.5, was established to reduce the outcome of promising changes in the background levels due to natural inputs. In this investigation, $B_{n}$ designates concentration of metal in earth crust [30, 31]. According to Muller [32], the contamination levels can be categorized as $I_{\text {geo }} \leq 0=$ practically uncontaminated, $0<I_{\text {geo }}<1=$ uncontaminated to moderately contaminated, $1<I_{\text {geo }}<2$ = moderately contaminated, $2<I_{\text {geo }}<3=$ moderately to heavily contaminated, $3<I_{\text {geo }}<4=$ heavily contaminated, $4<I_{\text {geo }}<5=$ heavily to extremely contaminated, and $5<I_{\text {geo }}$ $=$ extremely contaminated.

Enrichment factor (EF) represents the extent to which metals are enriched or reduced comparative to a particular source and can be used to segregate between metals contributed by human intrusions and those from geogenic provenance [33-35]. It is based on the normalization of a measured metal against a reference metal. Generally, $\mathrm{Al}, \mathrm{Ca}$, $\mathrm{Fe}, \mathrm{Mg}$, and $\mathrm{Mn}$ are used as the reference elements. In this study, EFs were computed using Fe as a reference metal using the following relationship:

$$
\mathrm{EF}=\frac{\left(C_{x} / C_{\text {ref }}\right)_{\text {Sample }}}{\left(C_{x} / C_{\text {ref }}\right)_{\text {Crust }}},
$$

where $C_{x}$ is the average concentration of metal of interest and $C_{\text {ref }}$ refers to mean concentration of reference element for normalization. EF values were interpreted as follows [36]: EF $<2$ indicated minimal enrichment, $\mathrm{EF}=2-5$ showed moderate enrichment, $\mathrm{EF}=5-20$ exhibited significant enrichment, $\mathrm{EF}=$ 20-40 manifested very high enrichment, and $\mathrm{EF}>40$ reflected extremely high enrichment.

\section{Results and Discussion}

3.1. Soil Characteristics and Metals Distribution. Hydrogen ion concentration $(\mathrm{pH})$ in the studied soil ranged 7.4-8.2 and 7.2-7.8 with average values of 7.8 and 7.6 in summer and winter, respectively. On the average basis, the levels of $\mathrm{pH}$ were observed slightly higher in summer than winter. Table 2 shows the statistical summary related to selected metals distribution based on pseudototal contents in surface soil in summer and winter. The results related to the distribution of the metals based on pseudototal contents in soil in summer and winter revealed that $\mathrm{Fe}$ (3993-5429 in summer and 2462$4171 \mathrm{mg} / \mathrm{kg}$ in winter), Mn (212-778 in summer and 179$561 \mathrm{mg} / \mathrm{kg}$ in winter), and Sr (47-1356 in summer and 62$739 \mathrm{mg} / \mathrm{kg}$ in winter) were the dominant contributors, while $\mathrm{Cd}(0.35-6.1$ in summer and $<0.01-5.2 \mathrm{mg} / \mathrm{kg}$ in winter) was the least participant in the studied soil in both seasons. On the arithmetic mean basis, the decreasing concentration order of the metals was $\mathrm{Fe}>\mathrm{Sr}>\mathrm{Mn}>\mathrm{Zn}>\mathrm{Pb}>\mathrm{Cr}>\mathrm{Cu}>$ $\mathrm{Co}>\mathrm{Cd}$ and $\mathrm{Fe}>\mathrm{Mn}>\mathrm{Sr}>\mathrm{Zn}>\mathrm{Co}>\mathrm{Cu}>\mathrm{Cr}>\mathrm{Pb}>$ $\mathrm{Cd}$ in summer and winter, successively. Total metal load of these selected metals varied as $4404-8376 \mathrm{mg} / \mathrm{kg}$ and $2784-$ $5731 \mathrm{mg} / \mathrm{kg}$ with mean values of $6061 \mathrm{mg} / \mathrm{kg}$ and $4585 \mathrm{mg} / \mathrm{kg}$ in summer and winter, respectively. Moreover the average levels of these metals were also found to be higher in summer than winter $(P<0.05)$. Overall, $\mathrm{Cd}, \mathrm{Sr}$, and $\mathrm{Pb}$ showed relatively higher coefficients of variance $(\mathrm{CV})$, demonstrating that these metals were highly influenced by anthropogenic activities in the study area.

In comparison with the results of urban soils in the previous study [20], it was found that the measured concentrations of selected metals in the current study in suburban soils were relatively higher than the reported levels in urban soils, indicating that there were intensive human intrusions in suburban soils. The order of selected metals distribution was also found different from that of previous study. Furthermore, the estimated levels of selected metals were found higher in summer than winter in suburban soils whereas in previous study [20] the measured levels for most of the metals were noted to be higher in winter than summer, indicating that these results were entirely different from the reported results related to urban soils. 
TABLE 2: Descriptive statistics of pseudototal $(T, \mathrm{mg} / \mathrm{kg})$ and bioavailable $(B, \%)$ concentrations of selected metals in summer and winter.

\begin{tabular}{|c|c|c|c|c|c|c|c|c|c|}
\hline & Variable & Min & $\operatorname{Max}$ & Median & Arith. mean & Geo. mean & Har. mean & Skew. & CV (\%) \\
\hline \multirow{9}{*}{ Summer } & $\mathrm{Cd}_{T}$ & 0.35 & 6.1 & 3.7 & 3.6 & 3.1 & 2.3 & -0.28 & 47 \\
\hline & $\mathrm{Co}_{T}$ & 18 & 44 & 35 & 32 & 31 & 30 & -0.20 & 23 \\
\hline & $\mathrm{Cr}_{T}$ & 33 & 86 & 54 & 54 & 53 & 52 & 0.48 & 22 \\
\hline & $\mathrm{Cu}_{T}$ & 29 & 421 & 38 & 51 & 41 & 38 & 5.4 & 138 \\
\hline & $\mathrm{Fe}_{T}$ & 3993 & 5429 & 4887 & 4863 & 4851 & 4839 & -0.64 & 7.0 \\
\hline & $\mathrm{Mn}_{T}$ & 212 & 778 & 392 & 435 & 404 & 376 & 0.41 & 39 \\
\hline & $\mathrm{Pb}_{T}$ & 0.99 & 112 & 54 & 57 & 45 & 18 & 0.21 & 52 \\
\hline & $\mathrm{Sr}_{T}$ & 47 & 1356 & 251 & 468 & 289 & 183 & 1.1 & 96 \\
\hline & $\mathrm{Zn}_{T}$ & 70 & 143 & 96 & 98 & 96 & 95 & 0.69 & 17 \\
\hline \multirow{9}{*}{ Winter } & $\mathrm{Cd}_{T}$ & $<0.01$ & 5.2 & 1.6 & 1.8 & 1.2 & 0.52 & 0.75 & 71 \\
\hline & $\mathrm{Co}_{T}$ & 18 & 43 & 30 & 31 & 30 & 30 & 0.34 & 19 \\
\hline & $\mathrm{Cr}_{T}$ & 2.5 & 32 & 24 & 23 & 21 & 17 & -1.3 & 30 \\
\hline & $\mathrm{Cu}_{T}$ & 17 & 44 & 27 & 28 & 27 & 26 & 0.59 & 21 \\
\hline & $\mathrm{Fe}_{T}$ & 2462 & 4171 & 3921 & 3802 & 3786 & 3766 & -2.5 & 8.6 \\
\hline & $\mathrm{Mn}_{T}$ & 179 & 561 & 408 & 393 & 378 & 361 & -0.46 & 26 \\
\hline & $\mathrm{Pb}_{T}$ & 2.4 & 45 & 16 & 19 & 15 & 10 & 0.47 & 67 \\
\hline & $\mathrm{Sr}_{T}$ & 62 & 739 & 160 & 225 & 183 & 157 & 2.0 & 80 \\
\hline & $\mathrm{Zn}_{T}$ & 41 & 91 & 61 & 62 & 60 & 59 & 0.47 & 22 \\
\hline \multirow{9}{*}{ Summer } & $\mathrm{Cd}_{B}$ & 0.11 & 70 & 2.2 & 5.6 & 2.3 & 1.2 & 4.6 & 235 \\
\hline & $\mathrm{Co}_{B}$ & 0.39 & 2.5 & 1.3 & 1.3 & 1.1 & 1.0 & 0.32 & 46 \\
\hline & $\mathrm{Cr}_{B}$ & $<0.01$ & 0.83 & 0.26 & 0.32 & 0.20 & 0.06 & 0.51 & 73 \\
\hline & $\mathrm{Cu}_{B}$ & 0.03 & 0.62 & 0.39 & 0.37 & 0.33 & 0.24 & -0.45 & 37 \\
\hline & $\mathrm{Fe}_{B}$ & $<0.01$ & 0.17 & 0.02 & 0.03 & 0.02 & 0.01 & 3.4 & 118 \\
\hline & $\mathrm{Mn}_{B}$ & $<0.01$ & 0.04 & 0.01 & 0.01 & 0.01 & 0.01 & 1.1 & 64 \\
\hline & $\mathrm{Pb}_{B}$ & 0.03 & 65 & 2.5 & 7.4 & 1.97 & 0.38 & 5.4 & 330 \\
\hline & $\mathrm{Sr}_{B}$ & 0.11 & 2.9 & 0.70 & 0.76 & 0.62 & 0.49 & 2.3 & 70 \\
\hline & $\mathrm{Zn}_{B}$ & 0.05 & 0.28 & 0.13 & 0.15 & 0.14 & 0.12 & 0.47 & 39 \\
\hline \multirow{9}{*}{ Winter } & $\mathrm{Cd}_{B}$ & 2.5 & 79 & 7.7 & 25 & 10 & 6.4 & 4.2 & 205 \\
\hline & $\mathrm{Co}_{B}$ & 0.36 & 6.7 & 2.8 & 2.6 & 2.3 & 1.8 & 0.68 & 49 \\
\hline & $\mathrm{Cr}_{B}$ & 0.02 & 1.4 & 0.31 & 0.46 & 0.33 & 0.20 & 1.2 & 76 \\
\hline & $\mathrm{Cu}_{B}$ & 0.01 & 0.81 & 0.26 & 0.27 & 0.17 & 0.07 & 0.74 & 77 \\
\hline & $\mathrm{Fe}_{B}$ & $<0.01$ & 0.02 & 0.01 & 0.01 & $<0.01$ & $<0.01$ & 0.94 & 61 \\
\hline & $\mathrm{Mn}_{B}$ & $<0.01$ & 0.04 & 0.01 & 0.01 & $<0.01$ & $<0.01$ & 2.4 & 88 \\
\hline & $\mathrm{Pb}_{B}$ & 0.61 & 23 & 2.9 & 4.4 & 3.0 & 2.1 & 2.6 & 106 \\
\hline & $\mathrm{Sr}_{B}$ & 0.29 & 4.9 & 1.1 & 1.3 & 1.1 & 0.93 & 2.5 & 77 \\
\hline & $\mathrm{Zn}_{B}$ & 0.01 & 0.55 & 0.09 & 0.09 & 0.07 & 0.04 & 4.1 & 103 \\
\hline
\end{tabular}

3.2. Bioavailability. Potential bioavailability of the metals was also evaluated in the study area in summer and winter (Table 2). The results manifested the highest bioavailability by $\mathrm{Cd}(0.11-70 \%$ in summer and $2.5-79 \%$ in winter $), \mathrm{Pb}$ $(0.03-65 \%$ in summer and $0.61-23 \%$ in winter), Co $(0.39-$ $2.5 \%$ in summer and $0.36-6.7 \%$ in winter), and Sr (0.11$2.9 \%$ in summer and $0.29-4.9 \%$ in winter $)$, while $\mathrm{Fe}(<0.01-$ $0.17 \%$ in summer and $<0.01-0.02 \%$ in winter $)$, Mn $(<0.01-$ $0.04 \%$ in both seasons), and $\mathrm{Zn}(0.05-0.28 \%$ in summer and $0.01-0.55 \%$ in winter) were the least contributors towards potential bioavailability of the metals to soil biota in both seasons. Consequently, $\mathrm{Pb}, \mathrm{Cd}, \mathrm{Co}$, and $\mathrm{Sr}$ showed higher bioavailability, while $\mathrm{Fe}, \mathrm{Mn}$, and $\mathrm{Zn}$ indicated the least. On the arithmetic mean basis, the metals followed the decreasing bioavailable concentrations order: $\mathrm{Pb}>\mathrm{Cd}>\mathrm{Co}>\mathrm{Sr}>\mathrm{Cu}$ $>\mathrm{Cr}>\mathrm{Zn}>\mathrm{Fe}>\mathrm{Mn}$ and $\mathrm{Cd}>\mathrm{Pb}>\mathrm{Co}>\mathrm{Sr}>\mathrm{Cr}>\mathrm{Cu}$ $>\mathrm{Zn}>\mathrm{Mn}>\mathrm{Fe}$ in summer and winter, respectively. The results clearly revealed that the sequences of pseudototal and bioavailable contents of the metals were different from one another. Furthermore the leachability for $\mathrm{Cd}, \mathrm{Co}, \mathrm{Cr}$, and $\mathrm{Sr}$ was quite higher in winter, while $\mathrm{Pb}$ and $\mathrm{Zn}$ indicated higher bioavailability in summer $(P<0.05)$. However total metals load of these metals was relatively higher in summer than winter.

3.3. Ecological Risk Evaluation. The range and mean values of CF of selected metals in acid-extract of the soils around the reservoir in summer and winter are portrayed in Figure 2(a). 


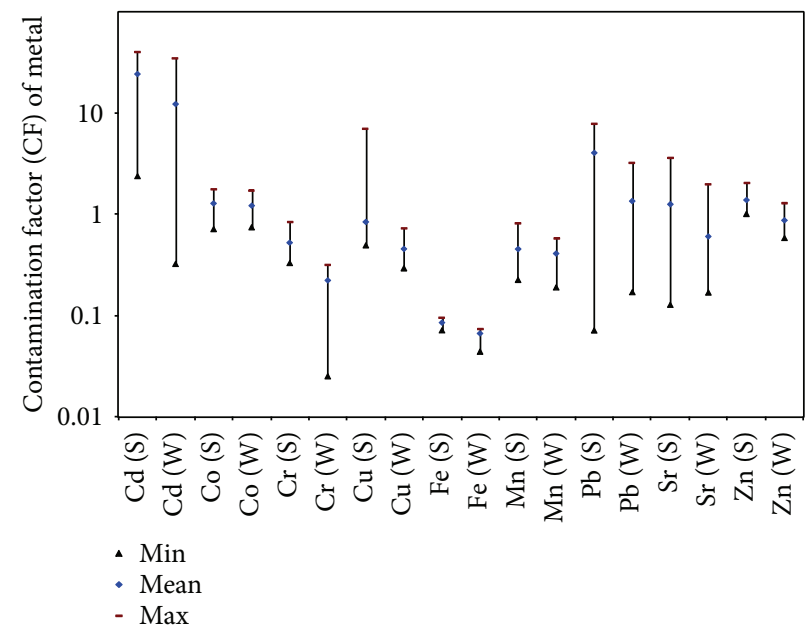

(a)

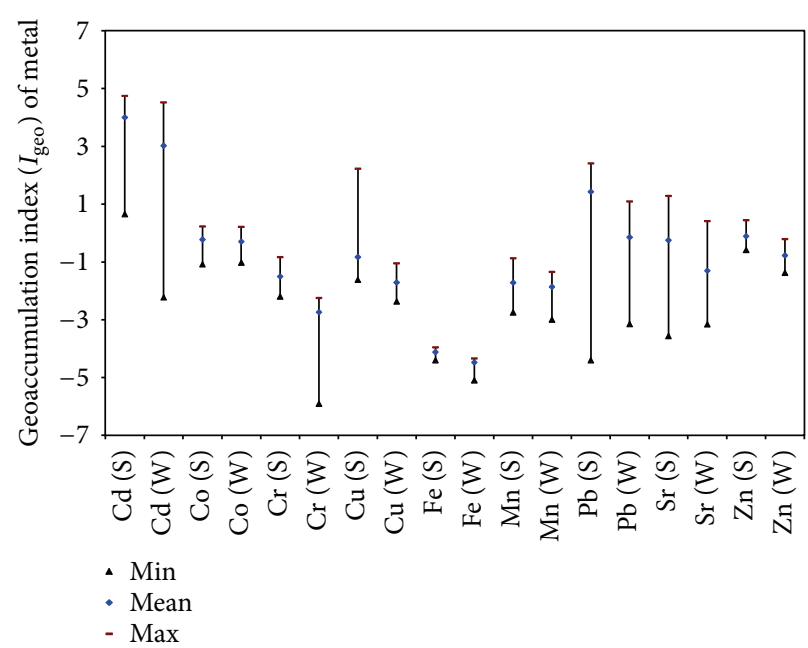

(b)

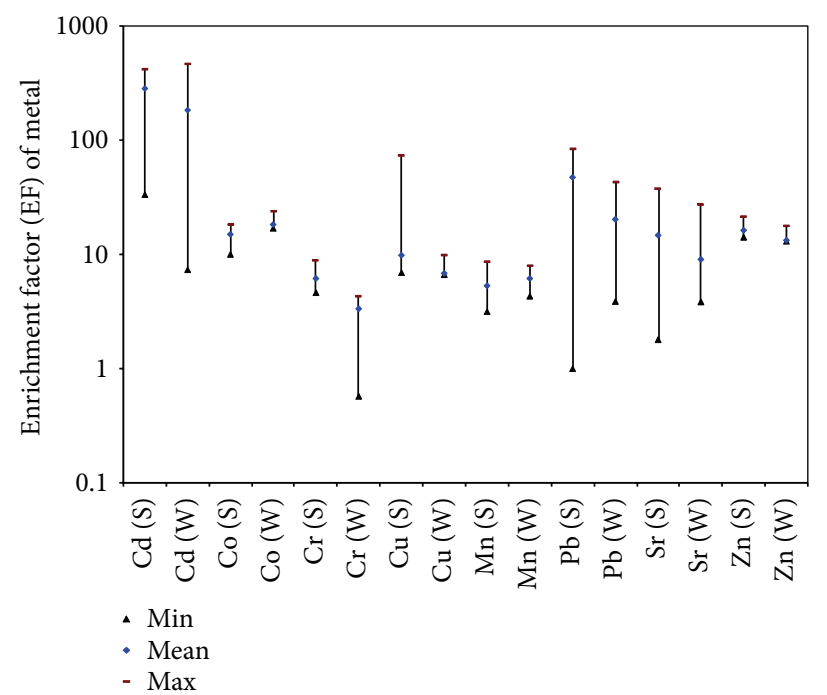

(c)

FIGURE 2: Description of contamination factor $(\mathrm{CF})$, geoaccumulation index $\left(I_{\text {geo }}\right)$, and enrichment factor $(\mathrm{EF})$ in soil in summer $(\mathrm{S})$ and winter (W).

In summer, on the average basis, $\mathrm{Co}, \mathrm{Sr}$, and $\mathrm{Zn}$ exhibited moderate contamination, $\mathrm{Pb}$ could cause considerable contamination, and $\mathrm{Cd}$ might pose very high contamination. The highest $\mathrm{CF}$ values of $\mathrm{Cd}, \mathrm{Cu}, \mathrm{Pb}, \mathrm{Sr}$, and $\mathrm{Zn}$ were 40.5 , 7.1, 8.0, 3.7, and 2.1, respectively, thus indicating that the soils were highly contaminated with $\mathrm{Cd}, \mathrm{Cu}$, and $\mathrm{Pb} ; \mathrm{Sr}$ might cause considerable contamination; and $\mathrm{Zn}$ moderate contamination in the soils. In winter, on mean scale, the soils demonstrated moderate contamination by $\mathrm{Co}$ and $\mathrm{Pb}$, while Cd showed very high contamination and the rest of the metals indicated low or no contamination of the soils. The CF manifested that $\mathrm{Co}, \mathrm{Sr}$, and $\mathrm{Zn}$ could cause moderate contamination, $\mathrm{Pb}$ showed considerable contamination, and $\mathrm{Cd}$ might pose very high contamination of the soils. Iron and Mn showed low contamination in the studied soils in both seasons. However, the highest CF values of Mn were 0.6 and 0.8 in summer and winter, respectively, indicating that it might cause contamination to the soils in the future. In comparison with the results of $\mathrm{CF}$ in the previous study [20], it was found that there was more extent of metals contamination in the suburban soils than urban soils due to intensive human intrusions in these areas. Moreover, the extent of metals contamination was found relatively higher in summer than winter in suburban soils whereas it was greater in winter than summer in urban soils [20].

The assessment of the soil based on the degree of contamination $\left(C_{\mathrm{deg}}\right)$ was also carried out as suggested by Hakanson [29]. It is considered as more appropriate parameter to assess the overall contamination by all measured metals in the soils and hence act as a cumulative index. The lowest to highest values of $C_{\mathrm{deg}}$ in summer and winter were 6.6-69.7 and 3.546.4 with the average values of 37.2 and 18.9, respectively. On the average basis, the soils belonged to very high degree of contamination class in summer, while considerable degree of 
TABle 3: Principal component loadings of selected metals in soil in summer and winter.

\begin{tabular}{|c|c|c|c|c|c|c|c|}
\hline & \multicolumn{3}{|c|}{ Summer } & \multicolumn{4}{|c|}{ Winter } \\
\hline & $\mathrm{PC} 1$ & $\mathrm{PC} 2$ & PC3 & $\mathrm{PC} 1$ & $\mathrm{PC} 2$ & PC3 & PC4 \\
\hline Eigen value & 2.8 & 2.3 & 1.5 & 2.3 & 1.8 & 1.5 & 1.2 \\
\hline$\%$ total variance & 36 & 25 & 17 & 25 & 21 & 17 & 13 \\
\hline$\%$ cumulative variance & 36 & 61 & 78 & 25 & 46 & 63 & 76 \\
\hline $\mathrm{Cd}$ & 0.80 & -0.13 & -0.20 & -0.18 & -0.08 & 0.76 & -0.21 \\
\hline Co & 0.87 & -0.07 & 0.07 & 0.05 & 0.12 & 0.90 & 0.10 \\
\hline $\mathrm{Cr}$ & 0.84 & 0.04 & 0.19 & 0.75 & 0.20 & 0.30 & 0.19 \\
\hline $\mathrm{Cu}$ & -0.24 & 0.17 & 0.88 & 0.35 & 0.07 & 0.14 & 0.79 \\
\hline $\mathrm{Fe}$ & 0.17 & 0.68 & -0.02 & -0.03 & 0.87 & -0.07 & -0.23 \\
\hline $\mathrm{Mn}$ & -0.36 & 0.82 & 0.11 & 0.88 & -0.06 & 0.03 & -0.09 \\
\hline $\mathrm{Pb}$ & 0.77 & -0.31 & 0.02 & 0.14 & 0.00 & 0.77 & 0.09 \\
\hline $\mathrm{Sr}$ & 0.91 & 0.08 & -0.02 & 0.74 & 0.09 & 0.33 & 0.07 \\
\hline $\mathrm{Zn}$ & 0.31 & -0.12 & 0.83 & -0.38 & 0.08 & -0.19 & 0.85 \\
\hline
\end{tabular}

contamination category in winter. Overall, higher contamination by selected metals was observed in summer compared to the winter in the studied soil. In comparison with the results of $C_{\mathrm{deg}}$ in urban soils in our previous study [20], it was noted that there was more degree of contamination in the suburban soils around the Khanpur Lake. Moreover, in this study, the levels of $C_{\text {deg }}$ were observed to be higher in summer than winter while in our previous study the values of $C_{\mathrm{deg}}$ were noted higher in winter than summer.

The contamination levels of selected metals were assessed using geoaccumulation index $\left(I_{\text {geo }}\right)$. Any increase in the current levels is envisaged to be anthropogenic in nature. Figure 2(b) describes the lowest, mean and highest $I_{\text {geo }}$ values of selected metals in acid-extract of the soils in summer and winter. In summer, mean values of $I_{\text {geo }}$ indicated that the soils were heavily to extremely contaminated by $\mathrm{Cd}$; $\mathrm{Pb}$ showed moderate contamination and the remaining metals exhibited practically no contamination of the soils. Maximum $I_{\text {geo }}$ value of Cd might cause heavy to extreme contamination; Co and $\mathrm{Zn}$ posed no contamination to moderate contamination; $\mathrm{Sr}$ caused moderate contamination; and $\mathrm{Pb}$ caused moderate to heavy contamination of the soils. In winter, on the average basis, $\mathrm{Cd}$ might pose heavy contamination, while the rest of the metals showed practically no contamination of the soils. The maximum values of $\mathrm{Cd}$ might cause heavy to extreme contamination, $\mathrm{Co}$ and $\mathrm{Sr}$ could pose moderate contamination, and $\mathrm{Pb}$ caused heavy contamination of the soils. Overall geoaccumulation index revealed accumulation of $\mathrm{Cd}, \mathrm{Co}, \mathrm{Pb}$, and $\mathrm{Sr}$ in both seasons, while $\mathrm{Zn}$ showed accumulation in soils in summer only. In current study, it was noted that there was more geoaccumulation of selected metals in suburban soils around the Khanpur Lake than in urban soils around Rawal Lake [20]. Moreover, in this study more geoaccumulation was observed in summer than winter whereas in the previous study higher geoaccumulation was observed in winter than summer.

Enrichment factor (EF) is a comparatively simple and easy tool to assess enrichment extent of elements in soils [3335]. The minimum, mean, and maximum EF values of the selected metals in acid-extract of the soil around the lake in summer and winter are shown in Figure 2(c). In summer, average $\mathrm{EF}$ values of $\mathrm{Co}, \mathrm{Cr}, \mathrm{Cu}, \mathrm{Mn}, \mathrm{Sr}$, and $\mathrm{Zn}$ revealed that the soils were significantly enriched with these metals, while $\mathrm{Cd}$ and $\mathrm{Pb}$ were observed to be extremely/highly enriched in the soils. The rest of the metals were not significantly enriched in the soils. The highest EF values of $\mathrm{Sr}$ and $\mathrm{Zn}(\mathrm{EF}=20-40)$ graded the soils as very highly enriched; and Cd (EF > 400), $\mathrm{Cu}(\mathrm{EF}>70)$, and $\mathrm{Pb}(\mathrm{EF}>80)$ classified the soils as extremely enriched. However, average EF results in winter showed that $\mathrm{Co}, \mathrm{Cu}, \mathrm{Mn}, \mathrm{Sr}$, and $\mathrm{Zn}$ were significantly enriched; $\mathrm{Cr}$ was moderately enriched; $\mathrm{Pb}$ was very highly enriched; and $\mathrm{Cd}$ was found to be extremely enriched in the soils. The rest of the metals showed deficiency to minimal enrichment in the soils. The highest EF values of $\mathrm{Cd}(\mathrm{EF}>450)$ and $\mathrm{Pb}(\mathrm{EF}>$ $40)$ categorized the soils as extremely enriched, and Co and Sr $(E F>20)$ indicated that the soils were highly enriched with these metals. Overall, the mean EF values of $\mathrm{Co}, \mathrm{Cu}$, $\mathrm{Mn}, \mathrm{Sr}$, and $\mathrm{Zn}$ graded the soils as significantly enriched in both seasons; Cr categorized as significantly enriched in summer and moderately enriched in winter; $\mathrm{Pb}$ classified as extremely enriched in summer and very highly enriched in winter; and Cd graded the soils as extremely enriched in both seasons. In comparison with the results of EF in urban soils around Rawal Lake [20], the calculated levels of EF were found relatively higher in the suburban soils around Khanpur Lake than in urban soils in the previous study. Moreover, in current study, the extent of pollution was found relatively higher in summer than winter while in our previous study the degree of pollution was found relatively higher in winter than summer.

3.4. Source Apportionment. PCA was applied to find out the sources of selected metals in the studied soil. In this study, three principal components (PCs) and four PCs with eigenvalues greater than 1 were extracted which explained about $78 \%$ and $76 \%$ of the total variance in the analyzed data in summer and winter, respectively. Principal component loadings of selected metals in summer and winter are described in Table 3. In summer, PC1 (36\% of total variance) showed positive loadings of $\mathrm{Cd}, \mathrm{Co}, \mathrm{Cr}, \mathrm{Pb}$, and $\mathrm{Sr}$; PC2 (25\% 
of total variance) exhibited higher loadings of Fe and Mn; and PC3 (17\% of total variance) had elevated loadings in favor of $\mathrm{Cu}$ and $\mathrm{Zn}$. Nevertheless in winter, PC1 (25\% variance) had positive associations of $\mathrm{Cr}, \mathrm{Mn}$, and $\mathrm{Sr}$; PC2 (21\% variance) indicated positive loading of Fe; PC3 (17\% variance) had higher loadings for $\mathrm{Cd}, \mathrm{Co}$, and $\mathrm{Pb}$; and $\mathrm{PC} 4$ (13\% variance) exhibited elevated loadings for $\mathrm{Cu}$ and $\mathrm{Zn}$. Cadmium, Co, $\mathrm{Cr}, \mathrm{Cu}, \mathrm{Mn}, \mathrm{Pb}, \mathrm{Sr}$, and $\mathrm{Zn}$ were likely to be contributed by anthropogenic intrusions, such as agricultural and industrial activities, discharge of untreated domestic wastes, sewage sludge, road runoff, and atmospheric deposition [1, 37-40]. Though Fe showed close association with Mn in summer even then it was supposed to be contributed mainly by geogenic inputs as it was not highlighted in ecological risk assessment in both seasons.

\section{Conclusions}

The present study showed divergent disparity of selected metals in surface soil around freshwater Khanpur Lake, Pakistan, in summer and winter. On the arithmetic mean basis, Fe, Sr, Mn, and $\mathrm{Zn}$ were the dominant metals, while $\mathrm{Cd}, \mathrm{Pb}, \mathrm{Co}$, and $\mathrm{Cr}$ were in lower concentrations in acidextract. However, $\mathrm{Cd}, \mathrm{Co}, \mathrm{Sr}$, and $\mathrm{Pb}$ were easily leachable and bioavailable to soil biota in the study area. In ecological risk assessment, contamination factor demonstrated moderate contamination by $\mathrm{Co}, \mathrm{Sr}$, and $\mathrm{Zn}$ and high contamination by $\mathrm{Cd}, \mathrm{Cu}$, and $\mathrm{Pb}$; geoaccumulation index indicated heavy to extreme contamination by $\mathrm{Cd}$ and heavy contamination by $\mathrm{Pb}$; enrichment factor revealed significant enrichment by $\mathrm{Co}, \mathrm{Cr}, \mathrm{Cu}, \mathrm{Mn}, \mathrm{Sr}$, and $\mathrm{Zn}$ and extreme enrichment by $\mathrm{Cd}$ and $\mathrm{Pb}$. Principal component analysis evidenced significant anthropogenic intrusions of $\mathrm{Cd}, \mathrm{Cr}, \mathrm{Co}, \mathrm{Cu}, \mathrm{Mn}, \mathrm{Pb}, \mathrm{Sr}$, and $\mathrm{Zn}$ in the soil. Overall considerable/high degree of contamination was found in the soil.

\section{Conflict of Interests}

The authors do not have any conflict of interests.

\section{Acknowledgments}

The authors are grateful to the Administration of Khanpur Lake, Islamabad, Pakistan, for their help during sample collection. Technical and financial help by Quaid-i-Azam University, Islamabad, Pakistan, to execute this project is also acknowledged.

\section{References}

[1] G.-L. Yuan, T.-H. Sun, P. Han, J. Li, and X.-X. Lang, "Source identification and ecological risk assessment of heavy metals in topsoil using environmental geochemical mapping: typical urban renewal area in Beijing, China," Journal of Geochemical Exploration, vol. 136, pp. 40-47, 2014.

[2] X. Chen, X. Xia, Y. Zhao, and P. Zhang, "Heavy metal concentrations in roadside soils and correlation with urban traffic in Beijing, China," Journal of Hazardous Materials, vol. 181, no. 13, pp. 640-646, 2010.
[3] D. S. Manta, M. Angelone, A. Bellanca, R. Neri, and M. Sprovieri, "Heavy metals in urban soils: a case study from the city of Palermo (Sicily), Italy," Science of the Total Environment, vol. 300, no. 1-3, pp. 229-243, 2002.

[4] Y. B. Sun, Q. X. Zhou, X. K. Xie, and R. Liu, "Spatial, sources and risk assessment of heavy metal contamination of urban soils in typical regions of Shenyang, China," Journal of Hazardous Materials, vol. 174, no. 1-3, pp. 455-462, 2010.

[5] G. M. Pierzynsky, J. T. Sims, and G. F. Vance, Soils and Environmental Quality, CRC Press, Taylor \& Francis Group, New York, NY, USA, 2005.

[6] L. Poggio, B. Vrščaj, R. Schulin, E. Hepperle, and F. A. Marsan, "Metals pollution and human bioaccessibility of topsoils in Grugliasco (Italy)," Environmental Pollution, vol. 157, no. 2, pp. 680-689, 2009.

[7] C. S. C. Wong, X. Li, and I. Thornton, "Urban environmental geochemistry of trace metals," Environmental Pollution, vol. 142, no. 1, pp. 1-16, 2006.

[8] Y. Li, X. Gou, G. Wang, Q. Zhang, Q. Su, and G. Xiao, "Heavy metal contamination and source in arid agricultural soil in central Gansu Province, China," Journal of Environmental Sciences, vol. 20, no. 5, pp. 607-612, 2008.

[9] D. Montagne, S. Cornu, H. N. Bourennane, D. Baize, C. Ratié, and D. King, "Effect of agricultural practices on trace-element distribution in soil," Communications in Soil Science and Plant Analysis, vol. 38, no. 3-4, pp. 473-491, 2007.

[10] N. Sezgin, H. K. Ozcan, G. Demir, S. Nemlioglu, and C. Bayat, "Determination of heavy metal concentrations in street dusts in Istanbul E-5 highway," Environment International, vol. 29, no. 7, pp. 979-985, 2004.

[11] Y.-J. Cui, Y.-G. Zhu, R.-H. Zhai et al., “Transfer of metals from soil to vegetables in an area near a smelter in Nanning, China," Environment International, vol. 30, no. 6, pp. 785-791, 2004.

[12] X. Y. Zhang, F. F. Lin, Y. G. Jiang, K. Wang, and X. L. Feng, "Variability of total and available copper concentrations in relation to land use and soil properties in Yangtze River Delta of China," Environmental Monitoring and Assessment, vol. 155, no. 1-4, pp. 205-213, 2009.

[13] X.-L. Zhong, S.-L. Zhou, Q. Zhu, and Q.-G. Zhao, "Fraction distribution and bioavailability of soil heavy metals in the Yangtze River Delta-a case study of Kunshan City in Jiangsu Province, China," Journal of Hazardous Materials, vol. 198, pp. 13-21, 2011.

[14] M. J. McLaughlin, R. E. Hamon, R. G. McLaren, T. W. Speir, and S. L. Rogers, "Review: a bioavailability-based rationale for controlling metal and metalloid contamination of agricultural land in Australia and New Zealand," Australian Journal of Soil Research, vol. 38, no. 6, pp. 1037-1086, 2000.

[15] L. Rodríguez, E. Ruiz, J. Alonso-Azcárate, and J. Rincón, "Heavy metal distribution and chemical speciation in tailings and soils around a $\mathrm{Pb}-\mathrm{Zn}$ mine in Spain," Journal of Environmental Management, vol. 90, no. 2, pp. 1106-1116, 2009.

[16] Y.-J. An and D. H. Kampbell, "Total, dissolved, and bioavailable metals at Lake Texoma marinas," Environmental Pollution, vol. 122, no. 2, pp. 253-259, 2003.

[17] A. L. Nolan, E. Lombi, and M. J. McLaughlin, "Metal bioaccumulation and toxicity in soils-why bother with speciation?" Australian Journal of Chemistry, vol. 56, no. 2-3, pp. 77-91, 2003.

[18] E. Meers, G. Du Laing, V. Unamuno et al., "Comparison of cadmium extractability from soils by commonly used single extraction protocols," Geoderma, vol. 141, no. 3-4, pp. 247-259, 2007. 
[19] X.-S. Luo, J. Ding, B. Xu, Y.-J. Wang, H.-B. Li, and S. Yu, "Incorporating bioaccessibility into human health risk assessments of heavy metals in urban park soils," Science of the Total Environment, vol. 424, pp. 88-96, 2012.

[20] J. Iqbal and M. H. Shah, "Distribution, correlation and risk assessment of selected metals in urban soils from Islamabad, Pakistan," Journal of Hazardous Materials, vol. 192, no. 2, pp. 887-898, 2011.

[21] USEPA, Microwave Assisted Acid Digestion of Sediments, Sludges, Soils, and Oils, Method 3051A, Office of Solid Waste and Emergency Response, US Government Printing Office, Washington, DC, USA, 2007.

[22] G. Shi, Z. Chen, C. Bi et al., "Comprehensive assessment of toxic metals in urban and suburban street deposited sediments (SDSs) in the biggest metropolitan area of China," Environmental Pollution, vol. 158, no. 3, pp. 694-703, 2010.

[23] M. Radojevic and V. N. Bashkin, Practical Environmental Analysis, The Royal Society of Chemistry, London, UK, 1999.

[24] S. M. Rodrigues, B. Henriques, J. Coimbra, E. Ferreira da Silva, M. E. Pereira, and A. C. Duarte, "Water-soluble fraction of mercury, arsenic and other potentially toxic elements in highly contaminated sediments and soils," Chemosphere, vol. 78, no. 11, pp. 1301-1312, 2010.

[25] StatSoft Inc, STATISTICA for Windows: Computer Programme Manual, StatSoft Inc., Tulsa, Okla, USA, 1999.

[26] J. A. Acosta, A. Faz, and S. Martinez-Martinez, "Identification of heavy metal sources by multivariable analysis in a typical Mediterranean city (SE Spain)," Environmental Monitoring and Assessment, vol. 169, no. 1-4, pp. 519-530, 2010.

[27] S. R. Tariq, M. H. Shah, N. Shaheen, M. Jaffar, and A. Khalique, "Statistical source identification of metals in groundwater exposed to industrial contamination," Environmental Monitoring and Assessment, vol. 138, no. 1-3, pp. 159-165, 2008.

[28] S. R. Tariq, N. Shaheen, A. Khalique, and M. H. Shah, "Distribution, correlation, and source apportionment of selected metals in tannery effluents, related soils, and groundwater-a case study from Multan, Pakistan," Environmental Monitoring and Assessment, vol. 166, no. 1-4, pp. 303-312, 2010.

[29] L. Hakanson, "An ecological risk index for aquatic pollution control. A sedimentological approach," Water Research, vol. 14, no. 8, pp. 975-1001, 1980.

[30] D. R. Lide, CRC Handbook of Chemistry and Physics, Geophysics, Astronomy, and Acoustics, Abundance of Elements in the Earth's Crust and in the Sea, Section 14, CRC Press, Boca Raton, Fla, USA, 85th edition, 2005.

[31] K. Loska, D. Wiechulła, and I. Korus, "Metal contamination of farming soils affected by industry," Environment International, vol. 30, no. 2, pp. 159-165, 2004.

[32] G. Muller, "Index of geoaccumulation in sediments of the Rhine River," GeoJournal, vol. 2, pp. 108-118, 1969.

[33] C. Reimann and P. de Caritat, "Distinguishing between natural and anthropogenic sources for elements in the environment: regional geochemical surveys versus enrichment factors," Science of the Total Environment, vol. 337, no. 1-3, pp. 91-107, 2005.

[34] S. Dantu, "Heavy metals concentration in soils of southeastern part of Ranga Reddy district, Andhra Pradesh, India," Environmental Monitoring and Assessment, vol. 149, no. 1-4, pp. 213-222, 2009.

[35] F. A. Vega, E. F. Covelo, B. Cerqueira, and M. L. Andrade, "Enrichment of marsh soils with heavy metals by effect of anthropic pollution," Journal of Hazardous Materials, vol. 170, no. 2-3, pp. 1056-1063, 2009.
[36] R. A. Sutherland, "Bed sediment-associated trace metals in an urban stream, Oahu, Hawaii," Environmental Geology, vol. 39, no. 6, pp. 611-627, 2000.

[37] T.-B. Chen, Y.-M. Zheng, M. Lei et al., "Assessment of heavy metal pollution in surface soils of urban parks in Beijing, China," Chemosphere, vol. 60, no. 4, pp. 542-551, 2005.

[38] C. Micó, L. Recatalá, M. Peris, and J. Sánchez, "Assessing heavy metal sources in agricultural soils of an European Mediterranean area by multivariate analysis," Chemosphere, vol. 65 , no. 5, pp. 863-872, 2006.

[39] L. Zhao, Y. Xu, H. Hou, Y. Shangguan, and F. Li, "Source identification and health risk assessment of metals in urban soils around the Tanggu chemical industrial district, Tianjin, China," Science of the Total Environment, vol. 468-469, pp. 654-662, 2014.

[40] S. Charlesworth, M. Everett, R. McCarthy, A. Ordóñez, and E. de Miguel, "A comparative study of heavy metal concentration and distribution in deposited street dusts in a large and a small urban area: Birmingham and Coventry, West Midlands, UK," Environment International, vol. 29, no. 5, pp. 563-573, 2003. 

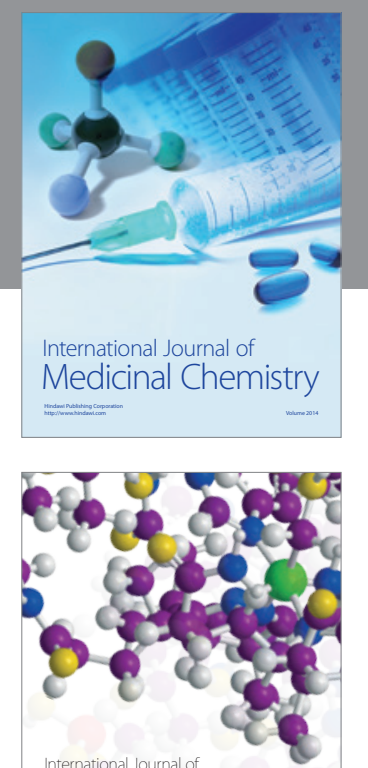

\section{Carbohydrate} Chemistry

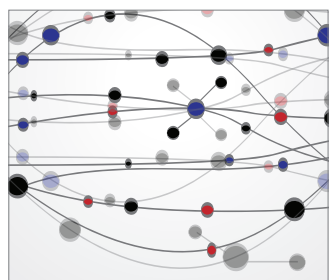

The Scientific World Journal
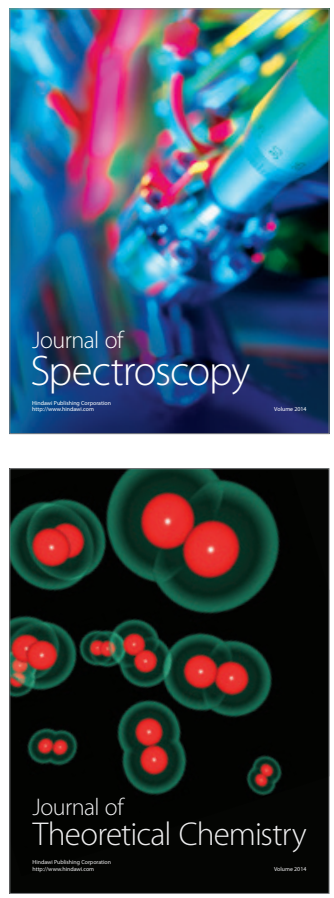
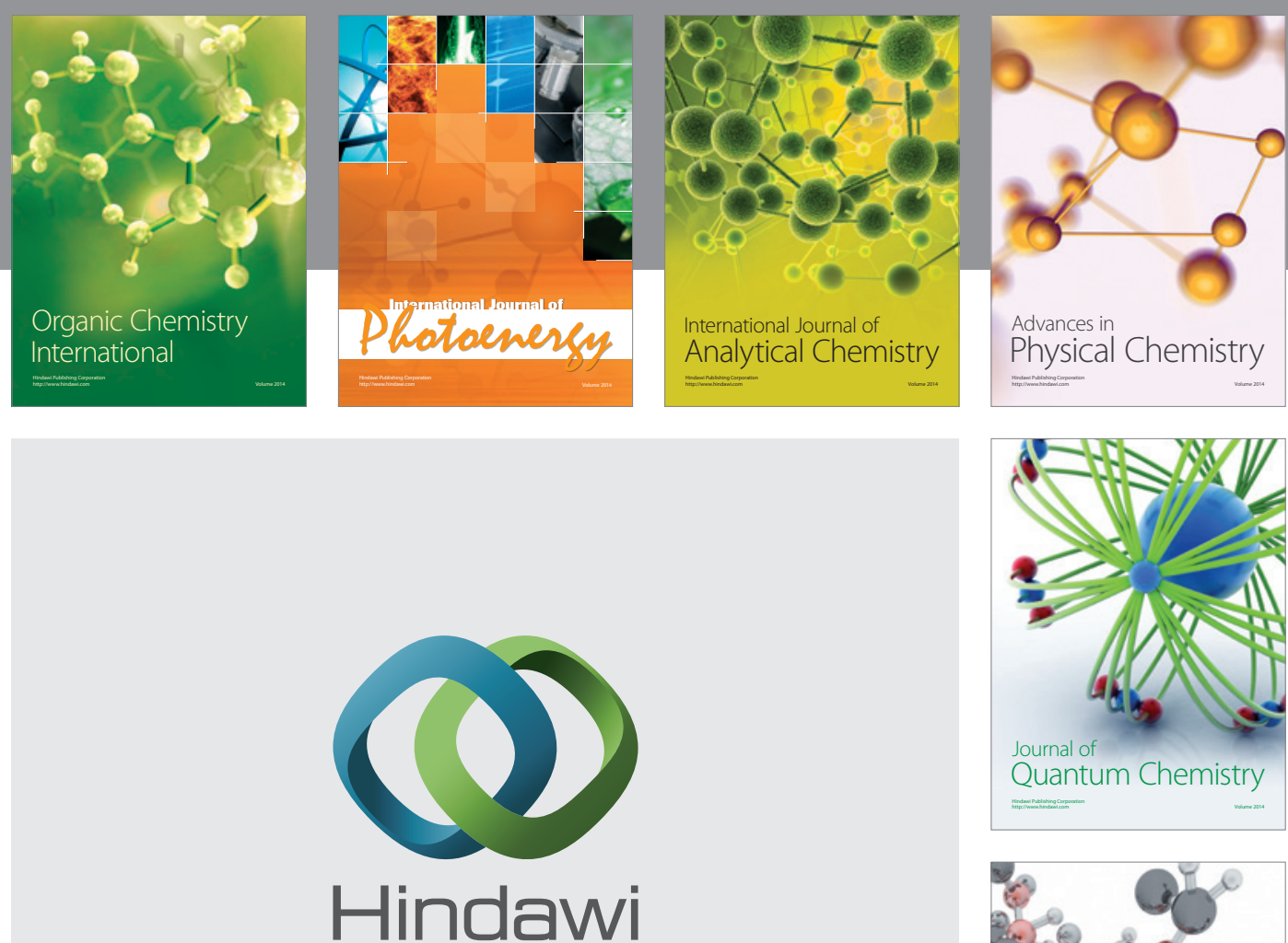

Submit your manuscripts at

http://www.hindawi.com

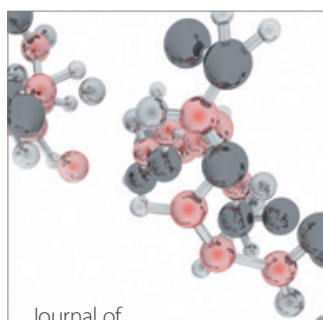

Analytical Methods

in Chemistry

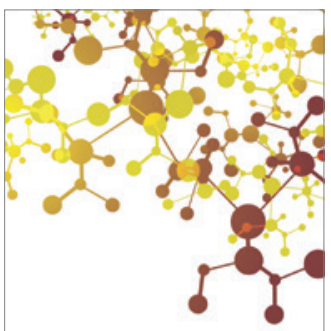

Journal of

Applied Chemistry

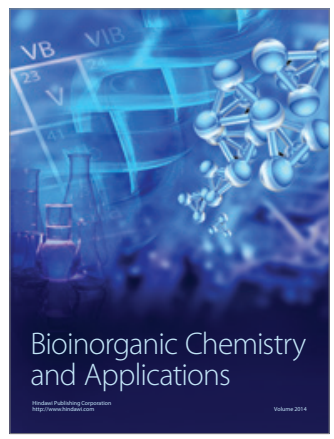

Inorganic Chemistry
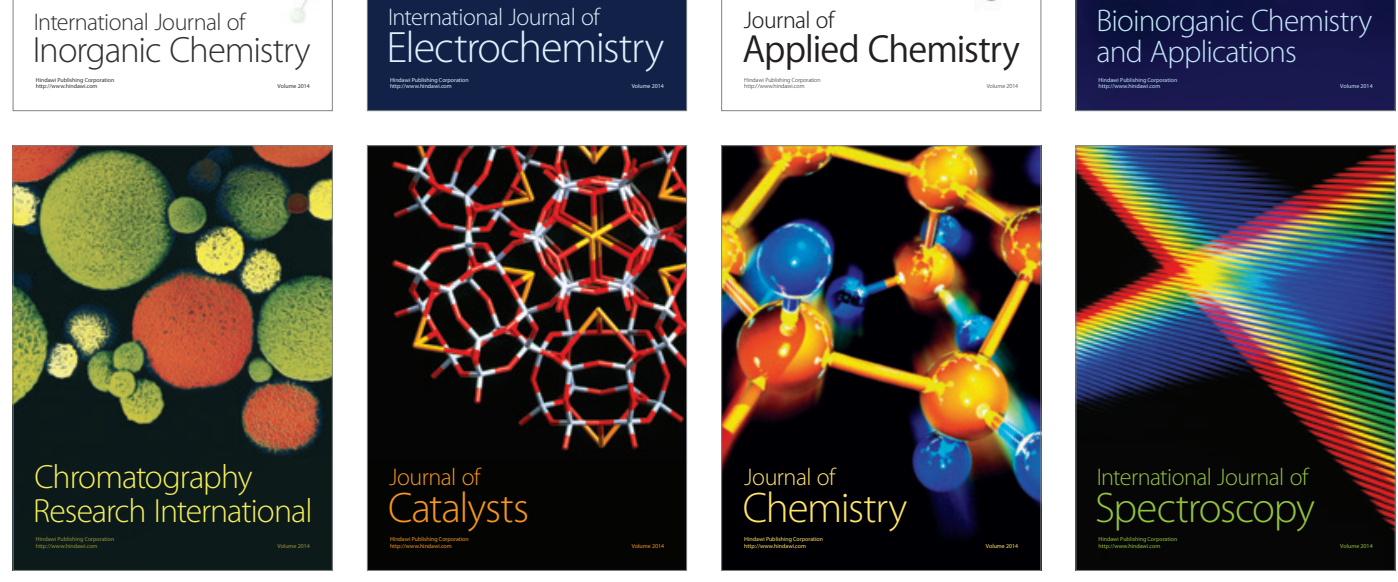